\title{
Mechanisms for Managing Ambidexterity: A Review and Research Agenda.
}

\begin{abstract}
$\underline{\text { Abstract }}$
Ambidexterity is of central importance to the competitive advantage of the firm, yet to date we have a limited understanding of how it is managed. The theorisation of ambidexterity is inadequate for complex, practical realities and in turn this hinders the way in which it can aid the management of ambidexterity in practice. This paper asks: what are the mechanisms for achieving ambidexterity? We use a systematic review to develop a research framework which integrates intellectual capital resources (organizational, social and human capital) across various levels of analysis (organization, group and individual). This review extends our understanding of the generic mechanisms (i.e., temporal, structural and contextual ambidexterity) which dominate the literature. This allows for a more fine-grained understanding of how ambidexterity is achieved and enables us to identify avenues for further research.
\end{abstract}

\section{Introduction}

Organizations within all sectors and markets face escalating pressure to serve their customers better by innovation in the delivery of goods and services, yet the competitive environment also demands ever-increasing operational efficiency. It is both a theoretical and practical challenge to balance the acts of innovation and efficiency within a single organizational unit. Herein lies the challenge and the contribution of this paper: how can we categorise (i) what resources are needed and (ii) the mechanisms that we can adopt, i.e. how we manage the simultaneity of renewal (innovation) and refinement (efficiency)? It is this simultaneity that 
we understand as ambidexterity. March (1991) identifies this tension between the twin requirements of exploration and exploitation. "Exploration includes things captured by terms such as search, variation, risk taking, experimentation, play, flexibility, discovery, innovation. Exploitation includes such things as refinement, choice, production, efficiency, selection, implementation, execution." (March, 1991:71). Short-term benefit may be obtained by exploitation, yet this may sacrifice long-term performance if the organization fails to adapt to the requirements of the market. Excessive focus on exploration, whereby an organization constantly seeks new ideas, may be similarly flawed (Levinthal and March, 1993). Neither of these options promote organizational longevity (O'Reilly and Tushman, 2011).

The argument put forward by Levinthal and March (1993:105) is that "[t]he basic problem confronting an organization is to engage in sufficient exploitation to ensure its current viability and, at the same time, to devote enough energy to exploration to ensure its future viability”. He and Wong (2004:481) advise:

"exploration and exploitation require substantially different structures, processes, strategies, capabilities, and cultures to pursue and may have different impacts on firm adaptation and performance. In general, exploration is associated with organic structures, loosely coupled systems, path breaking, improvisation, autonomy and chaos, and emerging markets and technologies. Exploitation is associated with mechanistic structures, tightly coupled systems, path dependence, routinization, control and bureaucracy, and stable markets and technologies."

Holmqvist (2009) reviews how either exploration or exploitation tends to drive out the other, making it difficult for organizations to achieve both, yet the challenge is to accommodate the 
two (Benner and Tushman, 2003). If these twin requirements compete for scarce organizational resources, then there is a trade-off to be made between them. This is an instinctively sensible approach, and in line with March (1991). There is, though, a growing body of scholarly work which focuses on ambidexterity (a term first used by Duncan, 1976) as a concept by which to consider the need to balance the requirements of exploitation and exploration and manage both effectively. However, there is a lack of consensus over exactly what this term means and how it can best be achieved (Cao et al., 2009; Gupta et al., 2006; Raisch et al., 2009). As we will show, there are a range of interpretations of the word, it has been used as a 'label' (Örtenblad, 2010) with multiple applications.

There is general agreement that achieving both exploitation and exploration can be beneficial in terms of financial performance (e.g. He and Wong, 2004; Kristal et al., 2010; Lubatkin et al., 2006; Morgan and Berthon, 2008) and increased organizational durability (O'Reilly and Tushman, 2011). Examples from a wide variety of industries and locations highlight the benefits of ambidexterity at the firm level. These include Canadian international new ventures (Han and Celly, 2008), high-technology firms in Taiwan (Li et al., 2008), Indian pharmaceutical firms (Kale and Wield, 2008), German high-tech start-ups (Kuckertz et al., 2010) and Spanish SMEs in the optometry and telecoms businesses (Cegarra-Navarro and Dewhurst, 2007). Care must be taken in interpreting its benefits, though, as a single factor such as sales growth rate (e.g. He and Wong, 2004) may be achieved by trading-off other aspects, whereas achieving multiple, potentially contradictory, objectives can be understood in terms of ambidexterity (Geraldi et al., 2011). Sarkees and Hulland (2009) found, in their survey of senior managers in publicly traded US firms, that an ambidextrous firm strategy has a positive effect on four dimensions of performance: revenues, profits, customer satisfaction, and new product introductions. They argue "[t]he fact that ambidextrous firms can outpace 
innovation-oriented firms in terms of new products is seemingly counterintuitive. Yet, it confirms that efficiency and innovation can be complementary rather than contradictory strategies, as other management researchers have suggested" (2009:49).

We must be careful, though, in proposing that ambidexterity is always beneficial, or indeed that it can be specifically identifiable in complex organizational systems (Sugarman, 2010). Ebben and Johnson (2005) studied small firms and found that those that followed efficiency or flexibility strategies outperformed those that attempted both. This is not entirely surprising, yet such results should caution scholars and practitioners that success via ambidexterity is not a foregone conclusion, and that consideration should be given as to the reasons why an ambidextrous strategy should be pursued, if it is to be attempted.

The increasing interest in ambidexterity, firstly as a means for achieving innovation and secondly from a theoretically rich background, has resulted in divergent approaches being applied. Both theory and empirical data have supported the benefits of an ambidextrous approach, yet a coherent understanding of the resources needed to enable ambidexterity, and a clear picture of how this may be achieved in practice, is lacking. This is captured by O'Reilly and Tushman (2011:8), “what is missing is a clear articulation of those specific managerial actions that facilitate the simultaneous pursuit of exploitation and exploration... what is needed is greater insight into the specific micro-mechanisms required for a manager to implement and operate an ambidextrous strategy." This is the gap that we address in the paper. We synthesise the current diverse body of research on ambidexterity into an organizing framework, and our contribution is to identify the mechanisms (i.e. processes, systems and structures) of ambidexterity. We categorise these by both the level of analysis (specifically at the organizational, group and individual levels) and by the underlying 
resources that underpin those mechanisms, operationalized in terms of intellectual capital (IC) (namely organizational, social and human capital).

The organizing framework was developed via a systematic literature review (Tranfield et al., 2003) which has been developed from the field of medicine, and provides a basis for rigorously and systematically examining the existing literature in line with a pre-defined search and evaluation strategy. This enables us to identify future research that will aid in the coalescence of existing ideas in this field of study, of benefit to both scholars and practitioners.

\section{Methodology}

A systematic review offers a comprehensive methodology for assessing current knowledge using a multi-stage review strategy (Pittaway et al., 2004). In this review, we followed the work of Tranfield et al. (2003), with the key points as summarised by Denyer and Neely (2004:133): the development of clear and precise aims and objectives; pre-planned methods; a comprehensive search of all potentially relevant articles; the use of explicit, reproducible criteria in the selection of articles; an appraisal of the quality of the research and the strength of the findings; a synthesis of individual studies using an explicit analytic framework; and a balanced, impartial and comprehensible presentation of the results. These aspects are now discussed.

The focus of this study was the mechanisms of ambidexterity. In order to meet the requirement of developing clear and precise aims and objectives, an initial scoping review of the literature was carried out. This identified that there are multiple organizational levels 
addressed within the literature, and that the processes, systems and structures are different at each level. The systematic review question was therefore proposed as:

\section{“What are the mechanisms for achieving ambidexterity at multiple organizational levels?"}

The lens through which this would be analysed was that of the intellectual capital resources which are used in each of the mechanisms. This allows the identification of the unique and valuable knowledge at both individual and collective levels within an organization that enables the production of goods or services (Swart, 2006). The review sought to categorise these mechanisms by the level of analysis and the IC resources employed. We consequently use an organizing framework to illustrate which IC resource (organizational, social or human capital) functions at which level (organization, group or individual) to enable these mechanisms to occur. This provides a clear picture synthesised from the diverse literature. The results of this are shown later as Table 3.

A review protocol was designed to address this question by searching for all 'ambidexterity' literature, with no pre-conceived expectations. In terms of data location, the search included peer-reviewed academic literature as well as practitioner literature, since many of the major articles have been aimed at practitioners. The search databases were ABI/Inform Proquest and EBSCO Business Source Premier, since they contain the major journals in which this subject is discussed.

The primary search string used was 'ambidex*' (to include the words 'ambidextrous' and 'ambidexterity'), and this returned 136 papers. This approach took 'ambidex*' as a broad, 'umbrella', term (Örtenblad, 2010). Tools were used to evaluate the papers identified: 
inclusion criteria; theoretical and empirical paper evaluation criteria; a quality assessment tool; a relevance assessment tool and a common data extraction format. Some papers were eliminated (executive summaries of papers within the issue, short practitioner articles or other uses of 'ambidexterity' outside the field of management). However, even with the systematic review and rating process, the intention was to be as inclusive as possible to avoid eliminating potentially valuable contributions in the study. A meta-analysis of the literature data (Dixon-Woods et al., 2004) was intended to provide a thorough summary of the theoretical issues raised by scholars, and also a review of the empirical research methods and findings, to gain an overall view of the state of knowledge in this area, with a view to understanding the underlying mechanisms.

From the 136 papers, 17 were eliminated, 34 were rated as conceptual and 85 were the results of empirical field research. Of these 85,26 were qualitative (based on cases and/or interviews) and 59 used survey data and subsequent statistical analysis. The journals in which these papers were published are listed in Table 1, along with the ABS 2010 journal rankings and it is noteworthy that $63 \%$ are rated as $3^{*}$ or $4^{*}$, indicating the academic significance of the subject.

Table 1: Journal Sources of Referenced Papers

\section{Ambidexterity: defining the concept}

From our review, we argue that the use of the word 'ambidexterity' within the literature does not reflect managerial activity, it reflects capability. Instead of being something that managers 'do', it is a way of looking at what they do. The concept has been taken by scholars 
to enlighten their field of study and has, as Simsek (2009) observes, entered multiple areas of research, including strategic management (Jansen et al., 2008; Lubatkin et al., 2006; Voelpel et al., 2006), innovation and technology management (Ambos et al., 2008; He and Wong, 2004; Tushman and O'Reilly, 1996), organizational learning (Levinthal and March, 1993), organization theory and behaviour (Benner and Tushman, 2003; Gibson and Birkinshaw, 2004) and operations management (Adler et al., 2009).

Raisch and Birkinshaw (2008:396) argue that organizational ambidexterity is taking shape as a research paradigm in organizational theory. They describe this paradigm as "a theoretical framework of a scientific school or discipline within which theories, generalisations, and the methods to test them are formulated". It should be noted that, despite such attention to the subject, few firms can actually achieve ambidexterity (Sarkees and Hulland, 2009), and hence further research into the nature of its mechanisms is important if the wider benefits are to be obtained by organizations.

It is clear that the increasing use of the word 'ambidexterity' within the literature has resulted in manifold uses of the terminology (Raisch and Birkinshaw, 2008). The interpretation has moved on from the organizational learning (OL) literature in which the concepts began, and indeed we argue that to conceive of ambidexterity as a subset of OL neglects the implications of the wider studies that have developed around the word. We follow Örtenblad (2010:449) and initially investigate the different meanings before offering our interpretation. Table 2 shows some of the varied definitions. Authors appear to have interpreted the concept of ambidexterity as the ability to pursue two contrasting objectives, which inherently leads to the creation of a tension that must be reconciled or accommodated (Andriopoulos and Lewis, 2010). Friedman et al. (2005:19-20) argue that "the so-called learning organization is 'a 
management Rorschach Test ${ }^{\prime 1}$ because one can see whatever one wants to see in this concept", and we view a corresponding issue within the field of ambidexterity. In this paper we therefore attempt to bring clarity to this diversity of views.

\section{Table 2: Definitions of Ambidexterity}

This range of meanings precludes a generic definition that usefully encompasses them all. Based on a synthesis of the ambidexterity literature, our interpretation is:

Ambidexterity is the ability to both use and refine existing knowledge (exploitation) whilst also creating new knowledge to overcome knowledge deficiencies or absences identified within the execution of the work (exploration).

The essence of our work is therefore to investigate the mechanisms by which this can be achieved, categorised by the IC resources needed and the organizational levels at which they occur. We base this in the terminology of March (1991) and accept that this necessarily omits some interpretations.

\section{Categorising the literature: a multi-level approach}

In reviewing the empirical literature (85 papers), we categorised the research into themes representing the levels of analysis of the studies. These were at the organization level (including firm performance, strategy, structure and operations, a total of 44 papers and by far the most prevalent), the group level (primarily the importance of social context and team interactions, total 9) and the individual level (emphasising the significance of the managerial

\footnotetext{
${ }^{1}$ Rorschach 'ink-blot test' as a psychological evaluation of personality.
} 
role, attributes and leadership behaviour, total 7), or a combination of these (grouporganization, 15; individual-organization, 6; individual-group, 4).

In order to further categorise the mechanisms, according to the resources needed at each level, we drew upon the framework of Kang and Snell (2009). They address the issue of how organizational resources are used in the process of ambidexterity. They consider the organization's knowledge assets (see also Blackler, 1995), and operationalise these in terms of intellectual capital (IC). This is a significant body of literature in itself (Swart, 2006), and beyond the scope of this work to review. However, Kang and Snell (2009) identify the subcomponents as organizational capital (OC, structures and processes within the firm), social capital (SC, knowledge embedded within the network of relationships) and human capital (HC, skills embodied within individuals). Importantly, they propose that these can be characterised with both exploitative and exploratory elements. HC can be specialist (e.g. technical expertise - exploitative) or generalist (such as wide-ranging management experience - exploratory) yet exists in the heads of individuals (Bontis, 1998; Hedberg, 1981). A cooperative (exploitative) approach to SC uses dense social networks, for example, established teams with strong ties; whereas an entrepreneurial (exploratory) approach uses a network of weaker ties to seek new knowledge (Burt, 1992; Granovetter, 1973; Hansen, 1999; Reagans and McEvily, 2003). OC, in which organizational knowledge is preserved (Daft and Weick, 1984) can be mechanistic or organic in nature (Burns and Stalker, 1961). The knowledge assets are therefore identifiable in six discrete forms. Kang and Snell (2009) furthermore offer two alternative frameworks to build an ambidextrous organization, each synthesised using three of the six elements. They advocate either blending specialist HC and cooperative SC with organic OC (i.e. allowing more flexibility for close-knit experts), or combining generalist $\mathrm{HC}$ with entrepreneurial SC and mechanistic $\mathrm{OC}$ (i.e. imposing more 
rigour and control on loose-knit generalists). Intuitively this concurs with observed practice, but are these ideas supported by the body of empirical evidence on ambidexterity?

The review was undertaken by looking at the mechanisms at each level (organization, group, and individual), and deriving a further classification by looking at the resources, specifically intellectual capital (OC, $\mathrm{SC}, \mathrm{HC})$, that were needed to make the actions possible. This provides a very detailed categorisation as we can identify:

a) Which mechanisms enable ambidexterity.

b) Which IC resources (OC, SC, HC) are used within each mechanism.

c) At which level (organization, group, individual) of analysis the mechanism and the resource exist to enable ambidexterity.

This provides a clear matrix within which we can categorise the mechanisms. The resulting framework is shown in Table 3 and the empirical studies and theoretical arguments will now be framed in this way. We proceed to high-level forms of ambidexterity, then the mechanisms according to the underlying knowledge assets utilised, and how they can be understood through the levels.

\section{Table 3: A Multi-Level Categorisation of Ambidexterity Mechanisms}

\section{Generic mechanisms for achieving ambidexterity}

The three major, high-level, implementation approaches at the organizational level identified within the literature are those of temporal, structural and contextual ambidexterity, and these will now briefly be summarised. Tushman and O'Reilly (1996) show that during periods of 
incremental, evolutionary, improvement, an organization can focus on exploitative learning, becoming better at serving its markets. However, many markets experience discontinuous, revolutionary, change, with a radical organizational response required. This represents a temporal strategy, where exploitative and exploratory modes are distinguished by time (i.e. one mode follows the other and they are not co-existent). This is the punctuated equilibrium model of organizational ambidexterity, which may not be sufficient to understand many practical issues. The high-level temporal understanding is difficult to reconcile with the richness and complexity of the real organizations that we see, and hence its applicability may be rare. For example, Swart and Kinnie (2007) show how a marketing agency works both within a planned, longer-term framework at account level, and an accelerated shorter-term view to meet client needs, and how the ability to accommodate these is critical to organizational success.

O'Reilly and Tushman (2004) also identify structural ambidexterity, whereby firms can implement an ambidextrous approach by using separate business units to perform either standard operations or radical innovations. This is also advocated by, for example, Bower and Christensen (1995), and is the 'partitional' approach (Simsek et al., 2009), whereby one organizational unit focuses on exploitation, another on exploration. These structurally separate, loosely coupled, subsystems must be integrated at the senior team level (Benner and Tushman, 2003). Resources are allocated to each group, but it is important to ensure that tailored and appropriate processes are followed by each, since existing systems may be inappropriate for exploratory activities. This, therefore, helps overcome the fundamentally different organizational design requirements. In their study, O'Reilly and Tushman (2004) found that ambidextrous firms using this technique were significantly more successful in 
launching breakthrough products or services. It is necessary to distinguish the level of analysis here, because, as Raisch and Birkinshaw (2008:396-7) elaborate:

"choices about how to resolve the tension at one level of analysis are often resolved at the next level down. So for example, a business unit may become ambidextrous by creating two functions or subdivisions with different foci, a manufacturing plant may become ambidextrous by creating two different teams (one in charge of enhancements to flexibility and another in charge of efficiency improvements), and a single team may become ambidextrous by allocating different roles to each individual."

However, taking a more complicated organizational structure as the unit of analysis, where multiple coalitions, functions and departments interact, a holistic approach recognises the difficulty of fitting a simpler model to this environment. We must acknowledge that taking each domain on its own may give a different view, yet the more levels of hierarchy we attempt to consider within an organization, the less clear it is that a single model of ambidexterity can be usefully applied. Benner and Tushman (2003:242) argue for lower-level analysis of this capability, where "ambidextrous organizations are composed of multiple tightly coupled subunits that are themselves loosely coupled with each other. Within subunits the tasks, culture, individuals, and organizational arrangements are consistent, but across subunits tasks and cultures are inconsistent and loosely coupled." Gupta et al. (2006) also point out that exploratory research and development (R\&D) units can work effectively with slower-moving and standardised manufacturing and sales groups within an organization, so the boundary can be considered as less distinct in this case. However, within this example, the R\&D units will also incorporate standard, exploitative, administrative functions, and the manufacturing group could be trialling novel techniques alongside well-established 
processes. The literature does not appear to explicitly capture this complexity, and it is not clear that this reality is well-understood theoretically. In line with Gupta et al. (2006) and Raisch and Birkinshaw (2008), we argue that the lack of multi-level, multi-domain analysis of ambidexterity is limiting our understanding of the concept, and hence this represents an inadequacy within existing theory. The high-level approaches (e.g. Tushman et al., 2011) have not resulted in a synthesis of the actions managers can consider to achieve ambidexterity at the operating level in complex organizations.

These issues are in part due to the conception of the relationship between exploitation and exploration. For temporal and structural ambidexterity, the emphasis is on dualism where exploitation and exploration preclude one another. Farjoun (2010) contends that stability and change, in terms of exploitation and exploration, can be considered as a duality, whereby stability may enable change, and change may enable stability. Regarding their interdependence and complementarities, he comments: "Duality suggests instead that stability and change in different units and hierarchical levels may intertwine and depend on common practices and that rather than negating and displacing one another, they can mutually reinforce each other in a process of renewal." (2010:218). Furthermore, "the duality view casts doubts on organisations' ability to separate elements of stability and change so neatly. Individuals engaged in routine tasks exercise some degree of experimentation, and those engaged in creative tasks use routines to some degree." (2010:218).

The consideration of the constructs as a duality allows an enhanced understanding of ambidexterity. This informs our view of Gibson and Birkinshaw's (2004) approach. They identify business-unit level contextual ambidexterity, which they define as "the behavioural capacity to simultaneously demonstrate alignment and adaptability" (2004:209). The former 
refers to coherent business activities working towards a common goal (i.e. knowledge refinement / exploitation), whereas the latter refers to the capacity to reconfigure those activities as required by the task environment (i.e. knowledge renewal / exploration). They argue that a context characterised by a combination of stretch, discipline, support and trust facilitates this contextual ambidexterity, and the results of their survey support the link between this and organizational success. Again, this is challenging to reconcile with complicated organizational reality. Contextual ambidexterity infers a tendency towards resource homogeneity, which is inconsistent with the reality of most organizations which contain a multitude of dynamically interacting groups and skills.

The comparison of structural and contextual ambidexterity leads to a key theoretical discussion within the literature. Gupta et al. (2006) review the subject and debate whether the concepts of exploration and exploitation represent a continuum (corresponding to the dualism view), or whether they are in fact orthogonal (coexisting, not competing, emphasising duality). They argue that if the resources in a single domain are scarce and pursuing one path necessitates lack of investment in the other, as March (1991) contends, then they may be mutually exclusive. In an organizational form where these modes are structurally separated, the rationale of the units is clear. Within a single business unit demonstrating contextual ambidexterity, though, it is more reasonable to argue that there is no specific resource tradeoff (Gupta et al., 2006; Raisch et al., 2009) but that these are orthogonal dimensions (as tested by He and Wong (2004) and Cao et al. (2009)), i.e. both exploitation and exploration may be performed together without trade-off. Structural and contextual ambidexterity may also be considered as the end-points of a continuum. At one end is 'full' structural ambidexterity (characterised by the separation of the exploitative and exploratory units, combined with managerial oversight), at the other is organization-level contextual ambidexterity (inferring 
greater resource homogeneity). These are theoretically valuable yet neither captures the reality of most organizations which contain multiple, interacting, departments and groups.

Herein lies the problem. Ambidexterity is not yet fully established as an explicit managerial strategy, and the higher-level concepts in the literature are not sufficient to explain the realities of modern organizations. A knowledge of the mechanisms by which ambidexterity is achieved in such settings is vital to further the understanding of both scholars and practitioners. This is the gap that we address in the paper. We take this organizational complexity on board with a view to synthesising a coherent multi-level view of the subject of ambidexterity and its implementation, using the concepts of organizational, social and human capital. In the section that follows we present our discussion of the literature review which we have organized according to the dominant intellectual capital resource that is adopted, i.e. OS, SC or HC to achieve ambidexterity. In addition we consider whether the resource (IC) operates at the individual, group or organizational level. This enables us to present a finegrained account of the current literature on the mechanisms for ambidexterity, and this is the main contribution of the paper.

\section{The Role of Organizational Capital}

In this section we identify from the literature the structural and process mechanisms for achieving ambidexterity that are enabled by OC. When considering OC, it is important to look outside the boundaries of the firm, as well as within, to understand these mechanisms, as supply chain strategy can be utilised to offset internal weaknesses in either exploitation or exploration (Kristal et al., 2010; Luo and Rui, 2009; Russo and Vurro, 2010). 
The benefits of an internal structural partitioning mechanism (achieving both exploitation and exploration by separating them) in high-technology firms have been substantiated (e.g. Vinekar et al., 2006; Visscher and De Weerd-Nederhof, 2006). In implementing this, Menguc and Auh (2010) find that radical product innovation is best supported by an informal structure, whereas incremental innovation is best supported by a formal structure. However, Grover et al. (2007) identify that both rigid/formal and organic/informal structures can coexist to promote incremental and radical innovation, and we find this to be a more useful line of enquiry. It is unclear how these issues are reconciled. What guidance does the literature provide in this respect? O'Connor and DeMartino (2006) investigate how large organizations can foster radical innovations internally and caution that the structural separation approach may be insufficient to develop longer-term organizational capability. They identify that a model of discovery-incubation-acceleration is beneficial in supporting commercialisation. This adds more detail to the structural separation argument, and highlights the difficulty of creating long-term business benefit. It also shows that the distinction between exploitation and exploration is not so clear-cut under these conditions, further complicating potential guidance. The 'pure' structural approach to ambidexterity loses its value when we consider the nature of modern organizations, and multiple levels of hierarchy.

Similarly, there is a problem for process mechanisms in modern organizations. The multilevel context is also difficult to reconcile with a 'pure' model of temporal ambidexterity. Although the wider organization may be exhibiting exploitation or exploration, it is likely that a lower-level analysis would reveal aspects of the other form at any point in time, since there are always 'standard' processes being undertaken, together with new problems to overcome. 
How, then, can organizational structures and processes aid in ambidexterity? Brown (2004) describes how the firm must not only look after its core business, but also be cognisant of events at the periphery that may become mainstream. This may be accomplished by, for instance, establishing 'listening posts' or communities of practice. This stream of research is important as it shows how organizational ambidexterity may be underpinned by the enabling social dynamics, and the role of social capital is discussed shortly. Utilising these may be difficult, though. Judge and Blocker (2008) propose that organizational capacity for change is an antecedent of strategic ambidexterity, and Morgan and Berthon (2008) use an innovation strategy map to represent how exploration is a far more significant organizational shift than the exploitative equivalent. The challenge therefore is to understand better the mechanisms by which this can be accommodated within the particular context.

At the group level, the achievement of both exploitation and exploration can be supported by structure, but this is not necessarily sufficient. The evidence shows that this needs reward systems (processes) that encourage the support of both exploitation and exploration (Ambos et al., 2008; Chang et al., 2009), together with a long-term view and support for risk-taking (Brion et al., 2010; Sethi and Sethi, 2009). Processes for creating dense social relations and informal coordination mechanisms are also beneficial (Jansen et al., 2005; Jansen et al., 2006), although distributed teams require more rigour as the tacit knowledge is harder to share (Lee et al., 2006). Kaplan and Henderson (2005) additionally suggest that incentives and cognition co-evolve so that organizational competencies or routines are as much about building knowledge of 'what should be rewarded' as they are about 'what should be done', which is difficult under conditions of uncertainty. Creating and managing effective operating social structures and reward systems is therefore important at the group level, such that both 
exploitation and exploration can be supported. It is notable that this overlaps with the concept of social capital, and a clear delineation between OC and SC is challenging in this respect.

Much of the 'managerial role' literature is inextricably linked with the structural aspects (a key element underpinning structural ambidexterity theory). However, some elements of organizational practice can be identified separately. For instance, it is important to balance the use of established 'best practices' with allowing operational flexibility at managers' discretion (Matson and Prusak, 2003). The use of both formal and informal managerial integration and control mechanisms (processes), including cross-functional interfaces, also contribute to improved performance (Jansen et al., 2009; Tiwana, 2010). This is important in showing how both formality and informality are required to be balanced to achieve ambidexterity, and this can be part of the organizational structural and process design.

In summary, the literature review indicates that managers can influence exploitation and exploration at multiple levels when considered in terms of OC. Externally, they must be mindful of the wider network and supply chain and the rationale for those relationships. Internally, although structural separation of exploitative and exploratory elements is presented as an implementation mechanism, in complicated organizational structures this requires further refinement since this partitioning may be significantly more complex. At the group and individual levels, structure needs to be reinforced with both incentives and also practical routines to enable both the informal and formal mechanisms. The benefits of ambidexterity can be achieved through a combination of both the mechanistic (exploitative) and organic (exploratory) processes of organizational capital, i.e. they can be understood as co-existing and orthogonal. 


\section{$\underline{\text { The Role of Social Capital }}$}

In this section we discuss the nature and implications of relationships at all levels in achieving ambidexterity. The importance comes through strongly from the literature, and this social capital can be understood in terms of structural, affective and cognitive dimensions (Kang et al., 2007; Nahapiet and Ghoshal, 1998). The ability to exploit and explore depends upon access to the appropriate knowledge together with a social support structure, as also highlighted above in terms of its relationship to OC. Looking at the inter-firm level, links are influenced by organizational strategy, and Im and Rai (2008) support the view that exploitative and exploratory knowledge-sharing practices are reinforcing and synergistic in long-term inter-organizational relationships. Studies also confirm the benefit of ambidexterity when considered at the industrial network level. Lin et al. (2007) argue that ambidexterity in this context is the simultaneous and balanced presence of both existing and new partners in a firm's network of alliances, and Riccaboni and Moliterni (2009) conclude that companies able to dynamically combine exploitation and exploration occupy a stable position at the core of the network structure and enjoy competitive advantage.

At the operational level, these networks of relationships can be crucial to organizational performance. Tiwana (2008) provides a powerful conception of ambidexterity in terms of social ties. He looks at the effect of weak/bridging ties (for exploratory access) and strong ties (for exploitative access), based on the work of Burt (1992) and Granovetter (1973). He argues that a "network of collaborators with strong ties has greater capacity to implement innovative ideas, but has inherently lower capacity to generate them; a network that is rich in structural holes (i.e., greater bridging ties) has greater capacity to generate new ideas, but has a lower capacity to implement them... In other words, strong ties should complement bridging ties" 
(Tiwana, 2008:251-2). Using data from a large American services conglomerate, his research showed that a portfolio of both strong and bridging ties leads to effective knowledge integration, and that this positively influences ambidexterity. His explanation is that "[a] project team that simultaneously possesses strong ties and bridging ties will have access to a diverse array of specialised knowledge, perspectives, and skills and have the mechanisms to integrate that knowledge at the project level. This combination of tie characteristics is what Burt (1992) would describe as an ideal configuration” (Tiwana, 2008:259).

In a similar vein, Beckman (2006) looked at how firm behaviours were influenced by their founder members' previous employment affiliations. From a sample of 141 Silicon Valley firms, founders whose members came from the same company exhibited more exploitative behaviour, while those from many different companies were more exploratory. Those with both were more ambidextrous in their approach and, importantly, had higher levels of performance. These ideas allow us to understand better how the nature and management of social ties can enable ambidexterity at the group or organization level. The role of social support is also emphasised within the literature. Gulati and Puranam (2009) show that informal organizational operation can complement the formal structure, causing 'compensatory fit', which can aid ambidexterity, and Lee and MacMillan (2008) find that deploying both procedural knowledge and commonly-held values is positively related to firm subsidiary performance. Güttel and Konlechner (2009) provide a qualitative account of contextual ambidexterity using a case study approach, highlighting the importance of flexibility, cultural values and social norms. They identify that the management team maps out the boundaries of the 'strategic corridor' that the organization must keep within, monitoring rather than integrating the exploitative and exploratory activities. Considering these more subtle, social, aspects are harder to 'manage' in such a direct way. Similarly, 
Güttel et al. (2009), Katz (2005), Ketkar and Sett (2009), López-Cabrales et al. (2011) and McLaughlin et al. (2008) show that organizational culture and HR practices can support ambidexterity, but these must be considered in light of the prevailing market dynamics. Gratton and Erickson (2007) also consider the team leadership role, where ambidextrous leaders must focus both on task completion and sustaining individual relationships, emphasising the importance of the social aspects of the role.

To summarise the social capital perspective, relationships can underpin the achievement of ambidexterity. The simultaneous combination of both exploitative and exploratory aspects is evident in these studies, indicating that they are also orthogonal and complementary. The theoretical basis for this is best captured in the Tiwana (2008) concept of a network of ties such that working groups can most effectively access and integrate knowledge. Consideration and active management of these ties can be beneficial in supporting both exploitation and exploration, but these should be considered within the support structure of HR practices and the prevailing organizational culture.

\section{The Role of Human Capital}

In this section we consider the leadership and management aspects that have emerged as key contributors to ambidexterity (Lin and McDonough, 2011; Rosing et al., 2011). Within structural ambidexterity, these are the mechanism to reconcile exploitative and exploratory activities (Tushman et al., 2011). O'Reilly and Tushman (2008:200) advise that “ambidexterity is a specific capability embodied in senior leadership's learning and expressed through their ability to reconfigure existing organizational assets and competencies in a repeatable way to adapt to changing circumstances". If organizational units are structurally 
separated to achieve ambidexterity, it is the responsibility of the top management team (TMT) to ensure coordination such that, together, organizational strategy is executed. Jansen et al. (2008) identify that this may lead to conflict if individuals within the senior management team are responsible for those units, yet a strong and compelling shared vision can help resolve those conflicts, aiding both exploitative and exploratory efforts. Lubatkin et al. (2006) find that TMT behavioural integration positively influences ambidexterity, which positively influences firm performance. In line with this, Carmeli and Halevi (2009) theorise that TMT behavioural integration gives rise to behavioural complexity in a team, which in turn enables strategic decisions balancing exploitation and exploration. They argue that this ability to engage in a wide repertoire of behaviours provides key mechanisms that enable organizational ambidexterity, via the actions of the senior leaders.

This view is extended further by Nemanich and Vera (2009) who show that transformational leadership is positively related to ambidexterity, and Mom et al. (2009) show that managers' decision-making authority and participation in cross-functional interfaces are also positively related to ambidexterity. They emphasise the relatively large effect of personal coordination compared to more formal mechanisms. The interaction effects of the formal mechanisms with the personal coordination mechanisms are greater than the sum of their parts - the complementary contributions aid ambidexterity. This echoes the structural and social issues emphasising the benefits of both formality and informality in OC.

In addition to the leadership and management aspects of structural ambidexterity, Gibson and Birkinshaw's (2004) contextual ambidexterity research showed four ambidextrous behaviours in individuals. These were: taking the initiative outside their own job roles; cooperative behaviour; brokering, looking to build internal linkages; and multitasking, "comfortable 
wearing more than one hat" (Birkinshaw and Gibson, 2004:49). This conception of ambidexterity as embedded in mental models of operation is powerful and provides a significantly different view from many other authors. There is, though, limited theorisation regarding individual managerial ambidexterity (especially at lower levels of the organizational hierarchy) and what this means in practice. Interestingly, Dover and Dierk (2010) interpret the role of managers as more exploitative, leaders as more ambidextrous and entrepreneurs as more exploratory.

To summarise the human capital view, the findings indicate that specialist managerial expertise is required, yet this needs to be balanced with a flexible, wider overview of the organization, supporting the view that $\mathrm{HC}$ can also be considered as orthogonal.

In our review of the literature on the mechanisms which enable ambidexterity we applied the categorisations of (i) the type of intellectual capital resource needed and (ii) the level at which the resource is used (see Table 3). This presents, for the first time, a comprehensive analysis of how to achieve ambidexterity across multiple levels. We view this in line with O'Reilly and Tushman's (2008) dynamic capability argument, whereby ambidexterity is enabled by organizational asset reconfiguration, and the resulting framework (Table 3 ) is a powerful means with which to understand the mechanisms and asset usage underlying exploitation and exploration. The derivation of this table has highlighted some important aspects. Firstly, the empirical findings to date hint that the forms of intellectual capital are orthogonal and co-existing. Secondly, it is difficult to disentangle and categorise the elements within Table 3, inferring that they are interwoven. Indeed, Kang and Snell (2009:86) suggest that "human, social, and organizational capital are conceptually distinct, the three may be related in practice - one may affect the others." The existence of these elements in 
combination supports this, and to consider a 'simple' model may be an insufficient theorisation of ambidexterity.

\section{Conclusions and Avenues for Future Research}

We conducted a systematic review to identify how IC resources (organizational, social and human capital) are used to enable ambidexterity at various levels (organizational, group and individual). This pinpoints the mechanisms for achieving exploitation and exploration at each level. In doing this, we build on the architectural perspective of Kang and Snell (2009) to offer a more flexible conceptualisation and framework (Table 3) which enables us to identify the mechanisms for managing ambidexterity. Through this work we have extended Kang and Snell's (2009) work in two ways. Firstly, we incorporated the duality perspective, recognising the orthogonal exploitative and exploratory IC elements at each level, rather than conceiving of them as either/or. Secondly, we identify the entanglement of the different forms of capital, addressing the issues the authors identify in their paper (highlighted above).

We posit that the role of management is to orchestrate the knowledge assets such that the most appropriate orientation (exploitative / exploratory / ambidextrous) is achieved to obtain the required organizational results. However, the options shown in Table 3 show that this is far from straightforward. Analysis of the previous research indicates that each form of intellectual capital (OC, SC, HC) can be interpreted as orthogonal and co-existing in both exploitative and exploratory forms. Also, and importantly, it is difficult in practice to delineate between the forms of IC (i.e. the level of knowledge resource). They appear to be inherently related and mutually reinforcing with complex interactions. It is similarly challenging to identify exploitation as separate from exploration, reinforcing the duality 
conception of the subject (Farjoun, 2010). To consider any single aspects of the analysis in isolation neglects some of the operational mechanisms on which it relies.

This makes sense if we conceive of the organization as a complicated, dynamic, configuration of multiple departments, or a matrix structure serving a project-based business. We can readily envisage the dual aspects of organizational capital allowing controlled processes to enable smooth functioning, with the flexibility to adapt to the situation at hand. This is beneficial in complex scenarios when the work cannot be scripted perfectly in advance. Similarly we can conceive of the social aspects as balancing the (exploitative) stronger ties for complex knowledge-sharing with weaker (exploratory) ties to access new knowledge. Finally, we can understand both specialist and generalist HC operating within or outside the boundary of the organization. We have identified that there is a complex interweaving of these aspects (i.e. to consider one facet in isolation of the others misses key aspects of its practical operation), and recognising this entanglement further enriches our view of the subject. We therefore argue that to better understand the nature of ambidexterity, we must first acknowledge the complexities that are inherent in its operationalization. This is of importance to practitioners, who can consider their roles both in terms of the management of resources within their organizations (identified as the forms of IC), but also with respect to the mechanisms in Table 3.

This systematic review has shown that ambidexterity is emerging as an important area of scholarly theory and empirical investigation. However, there are areas that are worthy of future research. Specifically, there is a lack of generalisable theory regarding how ambidexterity can be understood as a deliberate strategy within a complex organizational structure. The conceptions of temporal, structural and contextual ambidexterity are well 
documented, yet the application of such constructs to a multi-level organizational configuration is difficult. The review has shown that current empirical work favours collective and structural approaches to ambidexterity, mostly quantitative, and there are a lower proportion of 'micro-level' studies of the mechanisms underlying the achievement of ambidexterity looking at the individual and social levels. These studies neither fully explain how such micro-mechanisms enable ambidexterity, nor exactly how ambidexterity leads to organizational benefit. Similarly, although the role of managers and management teams has been studied, relatively little has been demonstrated regarding how managers can actually orchestrate exploitation and exploration. The framework we have developed (Table 3) allows mechanisms to be considered either in terms of the underlying resources (by examining the vertical categorisation) or actions applicable at each level (horizontal), allowing both scholars and practitioners a more holistic, multi-level, understanding.

The role and interaction of organizational assets can offer valuable insight into the micromechanisms enabling ambidexterity, and as yet these have been underexplored. Studying this orchestration may present a clearer picture of ambidexterity at the micro-level than is currently understood using organizational-level themes of structural, contextual and temporal ambidexterity. Greater richness may be found by examining high- and low-novelty work, and the effect of discontinuities (such as critical incidents) that require managerial action. Qualitative investigations under circumstances such as these may provide further explanatory data to promote a more detailed understanding of the links between actions and benefits. This may also enable a greater clarity of the effects on, and perceptions of, employees working in an ambidextrous organization. 
Finally, a broader approach can be taken in considering the benefits of ambidexterity. The detailed operational mechanisms and linkages between ambidexterity and financial performance are not fully understood, yet we may look further than this in examining how developing this capability may itself offer differentiating advantage to the organization and be beneficial in enabling future competitiveness. Longitudinal studies may allow researchers to comprehend better how ambidexterity 'works in practice', including at the micro-level, to enhance our understanding of this subject, and its drivers and outcomes. Studies so far have not generally taken this approach, yet utilising such a basis for research allows a greater understanding of some of the issues raised within the literature, including how complex benefits unfold over time.

In summary, the key contribution of the paper is the identification of the mechanisms which support the achievement of ambidexterity. The prominent mechanisms were identified through a systematic review of the current literature. We have categorised these mechanisms according to the intellectual capital resource (OC, SC or $\mathrm{HC}$ ) and the level at which the particular mechanism operates (organizational, group or individual). This categorisation is presented in Table 3 and enables us to understand, in a fine-grained manner, how to achieve ambidexterity in practice. 
Table 1: Journal Sources of Referenced Papers

\begin{tabular}{|c|c|c|c|}
\hline Qty & Journal & Qty & Journal \\
\hline 12 & Organization Science $(4 *)$ & 1 & Business Horizons $(1 *)$ \\
\hline 7 & Academy of Mgt. Journal (4*) & 1 & Comms. of the ACM $\left(3^{*}\right)$ \\
\hline 7 & Journal of Mgt Studies $\left(4^{*}\right)$ & 1 & Creativity and Innovation Mgt. $\left(1^{*}\right)$ \\
\hline 6 & Harvard Business Review (4*) & 1 & European Journal of Marketing ( $3 *)$ \\
\hline 5 & Int. Journal of Tech. Mgt $\left(2^{*}\right)$ & 1 & European Mgt Jnl (2*) \\
\hline 3 & California Mgt. Review $\left(3^{*}\right)$ & 1 & European Mgt. Review $\left(1^{*}\right)$ \\
\hline 3 & Int. Journal of Innov. Mgt. (2*) & 1 & Entrepreneurship Theory and Practice (4*) \\
\hline 3 & Jour. Prod Innov. Mgt. (4*) & 1 & Human Relations $\left(4^{*}\right)$ \\
\hline 3 & Leadership Quarterly (4*) & 1 & Ind. and Corporate Change ( $\left.3^{*}\right)$ \\
\hline 3 & Long Range Planning $\left(3^{*}\right)$ & 1 & Information Systems Mgt. $(2 *)$ \\
\hline 3 & Management Decision $(1 *)$ & 1 & Information Sys. Research. $\left(4^{*}\right)$ \\
\hline 3 & Management Science $\left(4^{*}\right)$ & 1 & International Business Review (3*) \\
\hline 3 & MIT Sloan Mgt. Review (3*) & 1 & Int Jnl of Automotive Tech \& Mgt (--) \\
\hline 3 & Strategic Mgt. Journal (4*) & 1 & Int. Journal of HR Dev. \& Mgt. (--) \\
\hline 2 & Adv. in Dev. Human Res. $(2 *)$ & 1 & Jnl. of the Acad. of Marketing Sci $\left(3^{*}\right)$ \\
\hline 2 & IEEE Trans. Eng. Mgt (3*) & 1 & Journal of Business Chemistry (--) \\
\hline 2 & Industrial Marketing Mgt. (3*) & 1 & Journal of Business Strategy (--) \\
\hline 2 & Industry and Innovation $\left(2^{*}\right)$ & 1 & Journal of Int. Marketing (3*) \\
\hline 2 & Int. Journal of HR Mgt. $\left(3^{*}\right)$ & 1 & Journal of Marketing (4*) \\
\hline 2 & Jnl. of Applied Behav. Sci. (1*) & 1 & Journal of Mgt. Info. Sys. (3*) \\
\hline 2 & Journal of Change Mgt. $\left(1^{*}\right)$ & 1 & Journal of Operations Mgt. (4*) \\
\hline 2 & Jnl. Enterprise Culture (--) & 1 & Jnl. of Org. Change Mgt $\left(2^{*}\right)$ \\
\hline
\end{tabular}




\begin{tabular}{|l|l|l|l|}
\hline 2 & Journal of Management $\left(4^{*}\right)$ & 1 & Personnel Review $\left(2^{*}\right)$ \\
\hline 2 & R\&D Management (--) & 1 & Project Management Journal $\left(2^{*}\right)$ \\
\hline 2 & Schmalenbach Bus. Review (--) & 1 & Research Tech Management (--) \\
\hline 2 & Strategic Org (2*) & 1 & Research Policy (4*) \\
\hline 2 & Technovation $\left(2^{*}\right)$ & 1 & Strategy and Leadership (--) \\
\hline 1 & Academy of Mgt. Perspec. $\left(3^{*}\right)$ & & \\
\hline & & & TOTAL: 119 \\
\hline & & & \\
\hline
\end{tabular}


Table 2: Definitions of Ambidexterity

\begin{tabular}{|c|c|c|}
\hline Author(s) & Definition & Theoretical Perspective \\
\hline Achrol (1991) & $\begin{array}{l}\text { Simultaneous efficiency, innovation and } \\
\text { flexibility. }\end{array}$ & $\begin{array}{l}\text { Organization theory and } \\
\text { marketing strategy. }\end{array}$ \\
\hline $\begin{array}{l}\text { Tushman and } \\
\text { O’Reilly (1996) }\end{array}$ & $\begin{array}{l}\text { Able to manage both incremental and } \\
\text { revolutionary change (temporal } \\
\text { ambidexterity). }\end{array}$ & $\begin{array}{l}\text { Innovation and technology } \\
\text { management. }\end{array}$ \\
\hline $\begin{array}{l}\text { Benner and } \\
\text { Tushman (2003) }\end{array}$ & Exploitative and exploratory innovation. & $\begin{array}{l}\text { Innovation and technology } \\
\text { management. }\end{array}$ \\
\hline $\begin{array}{l}\text { Gibson and } \\
\text { Birkinshaw } \\
\text { (2004) }\end{array}$ & $\begin{array}{l}\text { ‘Contextual ambidexterity’ as } \\
\text { adaptability and alignment. }\end{array}$ & $\begin{array}{l}\text { Organization theory and } \\
\text { behaviour. }\end{array}$ \\
\hline $\begin{array}{l}\text { O’Reilly and } \\
\text { Tushman (2004) }\end{array}$ & $\begin{array}{l}\text { 'Structural ambidexterity', separation } \\
\text { between exploratory and exploitative } \\
\text { units. }\end{array}$ & Business strategy. \\
\hline $\begin{array}{l}\text { Graetz and } \\
\text { Smith (2005) }\end{array}$ & Controllability and responsiveness. & Organizational change. \\
\hline Moore (2005) & $\begin{array}{l}\text { Complex systems together with volume } \\
\text { operations. }\end{array}$ & Business strategy. \\
\hline $\begin{array}{l}\text { Ahn et al. } \\
\text { (2006) }\end{array}$ & $\begin{array}{l}\text { New product development both in terms } \\
\text { of business performance and knowledge } \\
\text { performance. }\end{array}$ & $\begin{array}{l}\text { Innovation and technology } \\
\text { management. }\end{array}$ \\
\hline Danneels (2006) & Developing and marketing both & Innovation and technology \\
\hline
\end{tabular}




\begin{tabular}{|l|l|l|}
\hline & sustaining and disruptive innovations. & management. \\
\hline Lee et al. (2006) & Balancing flexibility and rigour in global & Innovation and technology \\
software development, & management. \\
\hline Erickson (2007) & Leaders need to be task- and relationship- & Organizational behaviour. \\
teams. & The simultaneous and balanced presence & Organization theory and \\
\hline of both existing and new partners in a & behaviour. \\
\hline Hulland (2009) & firm's network of alliances. & \\
\hline Schreyögg and & Adaptable fluidity and efficient stability & Organization theory. \\
Sydow (2010) & & Marketing management. \\
\hline
\end{tabular}


Table 3: A Multi-Level Categorisation of Ambidexterity Mechanisms

\begin{tabular}{|c|c|c|c|c|}
\hline & & \multicolumn{3}{|c|}{ Intellectual Capital Resources } \\
\hline & & Organizational Capital & Social Capital & Human Capital \\
\hline \multirow{3}{*}{ 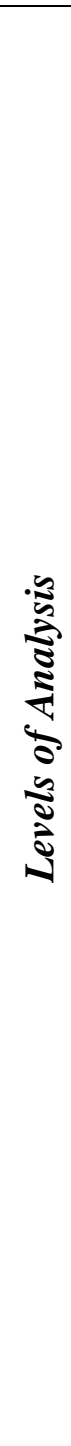 } & 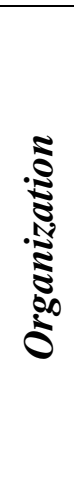 & $\begin{array}{c}\text { Structural } \\
\text { configuration and } \\
\text { separation. } \\
\text { Development and } \\
\text { maintenance of inter- } \\
\text { organizational } \\
\text { relationships. } \\
\text { Co-existence of formal } \\
\text { and informal structures. }\end{array}$ & $\begin{array}{l}\text { Knowledge-sharing } \\
\text { relationships with new } \\
\text { and existing external } \\
\text { parties. } \\
\text { HR practices supportive } \\
\text { of ambidexterity. }\end{array}$ & $\begin{array}{l}\text { Individuals reconcile } \\
\text { and coordinate } \\
\text { exploitative and } \\
\text { exploratory functions. } \\
\text { Management ability to } \\
\text { reconfigure } \\
\text { organizational assets. } \\
\text { TMT behavioural } \\
\text { integration and } \\
\text { complexity. }\end{array}$ \\
\hline & $\frac{5}{5}$ & $\begin{array}{c}\text { Reward systems to } \\
\text { support ambidexterity. } \\
\text { Processes for creating } \\
\text { dense social } \\
\text { relationships and } \\
\text { informal coordination. } \\
\text { Formal and informal } \\
\text { managerial integration } \\
\text { and control } \\
\text { mechanisms. }\end{array}$ & $\begin{array}{c}\text { Complex network of } \\
\text { strong and weak ties for } \\
\text { effective knowledge- } \\
\text { sharing, supported by } \\
\text { formal and informal } \\
\text { behaviours. } \\
\text { Relationships supportive } \\
\text { of ambidexterity. } \\
\text { Shared values and goals. }\end{array}$ & $\begin{array}{l}\text { Strong, compelling } \\
\text { vision. } \\
\text { Participation in cross- } \\
\text { functional interfaces. } \\
\text { Transformational } \\
\text { leadership. }\end{array}$ \\
\hline & 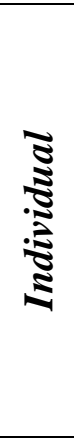 & $\begin{array}{c}\text { Multiple cross- } \\
\text { functional interfaces to } \\
\text { accommodate formal } \\
\text { and informal } \\
\text { coordination. } \\
\text { Use of both 'best- } \\
\text { practice' and local } \\
\text { managerial discretion } \\
\text { and judgement. }\end{array}$ & $\begin{array}{l}\text { Individuals creating and } \\
\text { supporting the context } \\
\text { for ambidexterity. } \\
\text { Both relational-and } \\
\text { task-focused leadership }\end{array}$ & $\begin{array}{l}\text { Taking the initiative; } \\
\text { cooperative behaviour; } \\
\text { multitasking; brokering. }\end{array}$ \\
\hline
\end{tabular}




\section{$\underline{\text { References }}$}

Achrol, R. S. (1991), "Evolution of the Marketing Organization: New Forms for Turbulent Environments", Journal of Marketing, vol. 55, no. 4, pp. 77-93.

Adler, P., Benner, M., Brunner, D., MacDuffie, J., Osono, E., Staats, B., Takeuchi, H., Tushman, M. and Winter, S. G. (2009), "Perspectives on the Productivity Dilemma", Journal of Operations Management, vol. 27, no. 2, pp. 99-113.

Ahn, J., Lee, D. and Lee, S. (2006), "Balancing Business Performance and Knowledge Performance of New Product Development: Lessons from ITS Industry", Long range planning, vol. 39 , no. 5, pp. 525-542.

Ambos, T. C., Mäkel, K., Birkinshaw, J. and D'Este, P. (2008), "When Does University Research Get Commercialized? Creating Ambidexterity in Research Institutions", Journal of Management Studies, vol. 45, no. 8, pp. 1424-1447.

Andriopoulos, C. and Lewis, M. W. (2010), "Managing Innovation Paradoxes: Ambidexterity Lessons from Leading Product Design Companies", Long range planning, vol. 43, no. 1, pp. 104-122.

Beckman, C. M. (2006), "The Influence of Founding Team Company Affiliations on Firm Behavior", Academy of Management Journal, vol. 49, no. 4, pp. 741-758.

Benner, M. J. and Tushman, M. L. (2003), "Exploitation, Exploration, and Process Management: the Productivity Dilemma Revisited", Academy of Management Review, vol. 28 , no. 2 , pp. $238-256$.

Birkinshaw, J. and Gibson, C. (2004), "Building Ambidexterity Into an Organization", MIT Sloan Management Review, vol. 45, no. 4, pp. 47-55.

Blackler, F. (1995), "Knowledge, Knowledge Work and Organizations: An Overview and Interpretation", Organization Studies (Walter de Gruyter GmbH \& Co.KG.), vol. 16, no. 6, pp. 1020.

Bontis, N. (1998), "Intellectual capital: An exploratory study that develops measures and models", Management Decision, vol. 36, no. 2, pp. 63.

Bower, J. L. and Christensen, C. M. (1995), "Disruptive Technologies: Catching the Wave", Harvard business review, vol. 73, no. 1, pp. 43-53. 
Brion, S., Mothe, C. and Sabatier, M. (2010), "The Impact of Organisational Context and Competences on Innovation Ambidexterity", International Journal of Innovation Management, vol. 14, no. 2, pp. 151-178.

Burns, T. and Stalker, G. (1961), The Management of Innovation. Tavistock, London.

Burt, R. (1992), Structural Holes: The Social Structure of Competition, Harvard University Press, Cambridge, Massachusetts.

Cao, Q., Gedajlovic, E. and Zhang, H. (2009), "Unpacking Organizational Ambidexterity: Dimensions, Contingencies, and Synergistic Effects", Organization Science, vol. 20, no. 4, pp. 781-796.

Carmeli, A. and Halevi, M. Y. (2009), "How top management team behavioral integration and behavioral complexity enable organizational ambidexterity: The moderating role of contextual ambidexterity", Leadership Quarterly, vol. 20, no. 2, pp. 207-218.

Cegarra-Navarro, J. and Dewhurst, F. (2007), "Linking organizational learning and customer capital through an ambidexterity context: an empirical investigation in SMEs", International Journal of Human Resource Management, vol. 18, no. 10, pp. 1720-1735.

Chang, Y., Yang, P. Y. and Chen, M. (2009), "The determinants of academic research commercial performance: Towards an organizational ambidexterity perspective", Research Policy, vol. 38, no. 6, pp. 936-946.

Daft, R. L. and Weick, K. E. (1984), "Toward a Model of Organizations as Interpretation Systems", Academy of Management Review, vol. 9, no. 2, pp. 284-295.

Danneels, E., ( 2006), Dialogue on the Effects of Disruptive Technology on Firms and Industries, Blackwell Publishing Limited.

Denyer, D. and Neely, A. (2004), "Introduction to special issue: Innovation and productivity performance in the UK", International Journal of Management Reviews, vol. 5/6, no. 3, pp. 131-135.

Dixon-Woods, M., Agarwal, S., Young, B., Jones, D. and Sutton, A. (2004), Integrative Approaches to Qualitative and Quantitative Evidence, , NHS Health Development Agency. 
Dover, P. A. and Dierk, U. (2010), "The ambidextrous organization: integrating managers, entrepreneurs and leaders", Journal of Business Strategy, vol. 31, no. 5, pp. 49-58.

Duncan, R. (1976), "The Ambidextrous Organization: Designing Dual Structures for Innovation", in Kilmann, R., Pondy, L. and Slevin, D. (eds.) The Management of Organization, Nort Holland, New York, pp. 167-188.

Ebben, J. J. and Johnson, A. C. (2005), "Efficiency, Flexibility, Or Both? Evidence Linking Strategy to Performance in Small Firms", Strategic Management Journal, vol. 26, no. 13, pp. 1249-1259.

Farjoun, M. (2010), "Beyond Dualism: Stability and Change as a Duality", Academy of Management Review, vol. 35, no. 2, pp. 202-225.

Friedman, V. J., Lipshitz, R. and Popper, M. (2005), "The Mystification of Organizational Learning", Journal of Management Inquiry, vol. 14, no. 1, pp. 19-30.

Geraldi, J. G., Kutsch, E. and Turner, N. (2011), "Towards a conceptualisation of quality in information technology projects", International Journal of Project Management, vol. 29, no. 5 , pp. 557-567.

Gibson, C. B. and Birkinshaw, J. (2004), "The Antecedents, Consequences, and Mediating Role of Organizational Ambidexterity", Academy of Management Journal, vol. 47, no. 2, pp. 209-226.

Graetz, F. and Smith, A. (2005), "Organizing forms in change management: The role of structures, processes and boundaries in a longitudinal case analysis", Journal of Change Management, vol. 5, no. 3, pp. 311-328.

Granovetter, M. (1973), "The Strength of Weak Ties", American Journal of Sociology, vol. 78, pp. 1360-1380.

Gratton, L. and Erickson, T. J. (2007), "8 Ways to Build Collaborative Teams", Harvard business review, vol. 85, no. 11, pp. 100-109.

Grover, V., Purvis, R. L. and Segars, A. H. (2007), "Exploring Ambidextrous Innovation Tendencies in the Adoption of Telecommunications Technologies", IEEE Transactions on Engineering Management, vol. 54, no. 2, pp. 268-285. 
Gulati, R. and Puranam, P. (2009), "Renewal Through Reorganization: The Value of Inconsistencies Between Formal and Informal Organization", Organization Science, vol. 20, no. 2, pp. 422-440.

Gupta, A. K., Smith, K. G. and Shalley, C. E. (2006), "The Interplay between Exploration and Exploitation", Academy of Management Journal, vol. 49, no. 4, pp. 693-706.

Güttel, W. H. and Konlechner, S. W. (2009), "Continuously Hanging by a Thread: Managing Contextually Ambidextrous Organizations", Schmalenbach Business Review (SBR), vol. 61, no. 2, pp. 150-172.

Guttel, W.H., Konlechner, S., Kohlbacher, F. and Haltmeyer, B., ( 2009), Strategies against competency obsolescence: the case of $R \& D$-intensive organisations.

Han, M. and Celly, N. (2008), "Strategic Ambidexterity and Performance in International New Ventures", Canadian Journal of Administrative Sciences, vol. 25, no. 4, pp. 335349.

Hansen, M. T. (1999), "The Search-Transfer Problem: The Role of Weak Ties in Sharing Knowledge across Organization Subunits", Administrative Science Quarterly, vol. 44, no. 1 , pp. 82-111.

He, Z. and Wong, P. (2004), "Exploration vs. Exploitation: An Empirical Test of the Ambidexterity Hypothesis", Organization Science, vol. 15, no. 4, pp. 481-494.

Hedberg, B. (1981), "How Organisations Learn and Unlearn", in Nystrom, P. C. and Starbuck, W. H. (eds.) Handbook of Organisational Design, Cambridge University Press, London, pp. 3.

Holmqvist, M. (2009), "Complicating the Organization: A New Prescription for the Learning Organization?", Management Learning, vol. 40, no. 3, pp. 275-287.

Im, G. and Rai, A. (2008), "Knowledge Sharing Ambidexterity in Long-Term Interorganizational Relationships", Management Science, vol. 54, no. 7, pp. 1281-1296.

Jansen, J. J. P., Tempelaar, M. P., van, d. B. and Volberda, H. W. (2009), "Structural Differentiation and Ambidexterity: The Mediating Role of Integration Mechanisms", Organization Science, vol. 20, no. 4, pp. 797-811. 
Jansen, J. J. P., Van, D. B. and Volberda, H. W. (2005), "Exploratory Innovation, Exploitative Innovation, and Ambidexterity: the Impact of Environmental and Organizational Antecedents", Schmalenbach Business Review (SBR), vol. 57, no. 4, pp. 351-363.

Jansen, J. J. P., Van, D. B. and Volberda, H. W. (2006), "Exploratory Innovation, Exploitative Innovation, and Performance: Effects of Organizational Antecedents and Environmental Moderators", Management Science, vol. 52, no. 11, pp. 1661-1674.

Jansen, J., George, G., Van den Bosch, F. and Volberda, H. W. (2008), "Senior Team Attributes and Organizational Ambidexterity: The Moderating Role of Transformational Leadership", Journal of Management Studies, vol. 45, no. 5, pp. 982-1007.

Judge, W. Q. and Blocker, C. P. (2008), "Organizational capacity for change and strategic ambidexterity Flying the plane while rewiring it", European Journal of Marketing, vol. 42, no. 9, pp. 915-926.

Kale, D. and Wield, D. (2008), "Exploitative and Explorative Learning as a Response to the TRIPS Agreement in Indian Pharmaceutical Firms", Industry \& Innovation, vol. 15, no. 1, pp. 93-114.

Kang, S., Morris, S. S. and Snell, S. A. (2007), "Relational Archetypes, Organizational Learning, and Value Creation: Extending the Human Resource Architecture", Academy of Management Review, vol. 32, no. 1, pp. 236-256.

Kang, S. and Snell, S. A. (2009), "Intellectual Capital Architectures and Ambidextrous Learning: A Framework for Human Resource Management", Journal of Management Studies, vol. 46, no. 1, pp. 65-92.

Kaplan, S. and Henderson, R. (2005), "Inertia and Incentives: Bridging Organizational Economics and Organizational Theory", Organization Science, vol. 16, no. 5, pp. 509521.

Katz, R. (2005), "Motivating Technical Professionals Today", Research Technology Management, vol. 48, no. 6, pp. 19-27.

Ketkar, S. and Sett, P. K. (2009), "HR flexibility and firm performance: analysis of a multilevel causal model", International Journal of Human Resource Management, vol. 20, no. 5, pp. 1009-1038. 
Kristal, M. M., Huang, X. and Roth, A. V. (2010), "The effect of an ambidextrous supply chain strategy on combinative competitive capabilities and business performance", Journal of Operations Management, vol. 28, no. 5, pp. 415-429.

Kuckertz, A., Kohtamaki, M. and Droege gen. Korber, C., (2010), The fast eat the slow - the impact of strategy and innovation timing on the success of technology-oriented ventures.

Lee, G., Delone, W. and Espinosa, J. A. (2006), "Ambidextrous Coping Strategies in Globally Distributed Software Development Projects", Communications of the ACM, vol. 49 , no. 10 , pp. $35-40$.

Lee, J. Y. and MacMillan, I. C. (2008), "Managerial knowledge-sharing in chaebols and its impact on the performance of their foreign subsidiaries", International Business Review, vol. 17 , no. 5 , pp. 533-545.

Levinthal, D. A. and March, J. G. (1993), "The Myopia of Learning", Strategic Management Journal, vol. 14, pp. 95-112.

Li, C., Lin, C. and Chu, C. (2008), "The nature of market orientation and the ambidexterity of innovations", Management Decision, vol. 46, no. 7, pp. 1002-1026.

Lin, H. and McDonough, E. F. (2011), "Investigating the Role of Leadership and Organizational Culture in Fostering Innovation Ambidexterity", IEEE Transactions on Engineering Management, vol. 58, no. 3, pp. 497-509.

Lin, Z., Yang, H. and Demirkan, I. (2007), "The Performance Consequences of Ambidexterity in Strategic Alliance Formations: Empirical Investigation and Computational Theorizing", Management Science, vol. 53, no. 10, pp. 1645-1658.

López-Cabrales, A., Valle, R. and Galan, J. L. (2011), "Employment relationships as drivers of firm flexibility and learning", Personnel Review, vol. 40, no. 5, pp. 625-642.

Lubatkin, M. H., Simsek, Z., Ling, Y. and Veiga, J. F. (2006), "Ambidexterity and Performance in Small- to Medium-Sized Firms: The Pivotal Role of Top Management Team Behavioral Integration", Journal of Management, vol. 32, no. 5, pp. 646-672.

Luo, Y. and Rui, H. (2009), "An Ambidexterity Perspective Toward Multinational Enterprises From Emerging Economies", Academy of Management Perspectives, vol. 23, no. 4 , pp. $49-70$. 
March, J. G. (1991), "Exploration and Exploitation in Organizational Learning", Organization Science, vol. 2, no. 1, pp. 71-87.

Matson, E. and Prusak, L. (2003), "The Performance Variability Dilemma", MIT Sloan Management Review, vol. 45, no. 1, pp. 39-44.

McLaughlin, P., Bessant, J. and Smart, P. (2008), "Developing an organisation culture to facilitate radical innovation", International Journal of Technology Management, vol. 44, no. 3, pp. 298-323.

Menguc, B. and Auh, S. (2010), "Development and return on execution of product innovation capabilities: The role of organizational structure", Industrial Marketing Management, vol. 39, no. 5, pp. 820-831.

Mom, T. J. M., Van den Bosch, F. and Volberda, H. W. (2009), "Understanding Variation in Managers' Ambidexterity: Investigating Direct and Interaction Effects of Formal Structural and Personal Coordination Mechanisms", Organization Science, vol. 20, no. 4, pp. 812-828.

Moore, G. A. (2005), "Strategy and Your Stronger Hand. (cover story)", Harvard business review, vol. 83 , no. 12 , pp. $62-72$.

Morgan, R. E. and Berthon, P. (2008), "Market Orientation, Generative Learning, Innovation Strategy and Business Performance Inter-Relationships in Bioscience Firms", Journal of Management Studies, vol. 45, no. 8, pp. 1329-1353.

Nahapiet, J. and Ghoshal, S. (1998), "Social Capital, Intellectual Capital, and the Organizational Advantage", Academy of Management Review, vol. 23, no. 2, pp. 242266.

Nemanich, L. A. and Vera, D. (2009), "Transformational leadership and ambidexterity in the context of an acquisition", Leadership Quarterly, vol. 20, no. 1, pp. 19-33.

O'Connor, G. C. and DeMartino, R. (2006), "Organizing for Radical Innovation: An Exploratory Study of the Structural Aspects of RI Management Systems in Large Established Firms", Journal of Product Innovation Management, vol. 23, no. 6, pp. 475497. 
O'Reilly, C. A. and Tushman, M. L. (2004), "The Ambidextrous Organization", Harvard business review, vol. 82, no. 4, pp. 74-81.

O'Reilly, C. A. and Tushman, M. L. (2011), "Organizational Ambidexterity in Action: How Managers Explore and Exploit", California management review, vol. 53, no. 4, pp. 5-22.

O'Reilly, C. A. and Tushman, M. (2008), "Ambidexterity as a Dynamic Capability: Resolving the Innovator's Dilemma", Research in Organizational Behavior, vol. 28, pp. 185-206.

Örtenblad, A. (2010), "Odd couples or perfect matches? On the development of management knowledge packaged in the form of labels", Management Learning, vol. 41, no. 4, pp. 443-452.

Pittaway, L., Robertson, M., Munir, K., Denyer, D. and Neely, A. (2004), "Networking and innovation: a systematic review of the evidence", International Journal of Management Reviews, vol. 5/6, no. 3, pp. 137-168.

Raisch, S. and Birkinshaw, J. (2008), "Organizational Ambidexterity: Antecedents, Outcomes, and Moderators", Journal of Management, vol. 34, no. 3, pp. 375-409.

Raisch, S., Birkinshaw, J., Probst, G. and Tushman, M. L. (2009), "Organizational Ambidexterity: Balancing Exploitation and Exploration for Sustained Performance", Organization Science, vol. 20, no. 4, pp. 685-695.

Reagans, R. and McEvily, B. (2003), "Network Structure and Knowledge Transfer: The Effects of Cohesion and Range", Administrative Science Quarterly, vol. 48, no. 2, pp. 240-267.

Riccaboni, M. and Moliterni, R. (2009), "Managing technological transitions through R\&D alliances", R\&D Management, vol. 39, no. 2, pp. 124-135.

Rosing, K., Frese, M. and Bausch, A. (2011), "Explaining the heterogeneity of the leadershipinnovation relationship: Ambidextrous leadership", Leadership Quarterly, vol. 22, no. 5, pp. 956-974.

Russo, A. and Vurro, C. (2010), "Cross-boundary ambidexterity: Balancing exploration and exploitation in the fuel cell industry", European Management Review, vol. 7, no. 1, pp. 30. 
Sarkees, M. and Hulland, J. (2009), "Innovation and efficiency: It is possible to have it all", Business horizons, vol. 52, no. 1, pp. 45-55.

Schreyögg, G. and Sydow, J. (2010), "Organizing for Fluidity? Dilemmas of New Organizational Forms", Organization Science, vol. 21, no. 6, pp. 1251-1262.

Seely Brown, J. (2004), "Minding and Mining the Periphery", Long Range Planning, vol. 37, no. 2 , pp. 143.

Sethi, R. and Sethi, A. (2009), "Can Quality-Oriented Firms Develop Innovative New Products?", Journal of Product Innovation Management, vol. 26, no. 2, pp. 206-221.

Simsek, Z. (2009), "Organizational Ambidexterity: Towards a Multilevel Understanding", Journal of Management Studies, vol. 46, no. 4, pp. 597-624.

Simsek, Z., Heavey, C., Veiga, J. F. and Souder, D. (2009), "A Typology for Aligning Organizational Ambidexterity's Conceptualizations, Antecedents, and Outcomes", Journal of Management Studies, vol. 46, no. 5, pp. 864-894.

Sugarman, B. (2010), "Organizational Learning and Reform at the New York City Police Department", Journal of Applied Behavioral Science, vol. 46, no. 2, pp. 157-185.

Swart, J. (2006), "Intellectual capital: disentangling an enigmatic concept", Journal of Intellectual Capital, vol. 7, no. 2, pp. 136.

Swart, J. and Kinnie, N. (2007), "Simultaneity of Learning Orientations in a Marketing Agency", Management Learning, vol. 38, no. 3, pp. 337-357.

Tiwana, A. (2008), "Do bridging ties complement strong ties? An empirical examination of alliance ambidexterity", Strategic Management Journal, vol. 29, no. 3, pp. 251-272.

Tiwana, A. (2010), "Systems Development Ambidexterity: Explaining the Complementary and Substitutive Roles of Formal and Informal Controls", Journal of Management Information Systems, vol. 27, no. 2, pp. 87-126.

Tranfield, D., Denyer, D. and Smart, P. (2003), "Towards a Methodology for Developing Evidence-Informed Management Knowledge by Means of Systematic Review", British Journal of Management, vol. 14, no. 3, pp. 207-222. 
Tushman, M. L. and O'Reilly, C. A. (1996), "Ambidextrous Organizations: Managing Evolutionary and Revolutionary Change", California Management Review, vol. 38, no. 4, pp. 8-30.

Tushman, M. L., Smith, W. K. and Binns, A. (2011), "The Ambidextrous CEO", Harvard business review, vol. 89, no. 6, pp. 74-80.

Vinekar, V., Slinkman, C. W. and Nerur, S. (2006), "Can Agile and Traditional Systems Development Approaches Coexist? an Ambidextrous View", Information Systems Management, vol. 23, no. 3, pp. 31-42.

Visscher, K. and De Weerd-Nederhof, P. C. (2006), "Rise and Fall of an Innovative Organisation:: the Innovation Journey of Ericsson Enschede", International Journal of Innovation Management, vol. 10, no. 3, pp. 217-235.

Voelpel, S. C., Leibold, M. and Tekie, E. B. (2006), "Managing purposeful organizational misfit: Exploring the nature of industry and organizational misfit to enable strategic change", Journal of Change Management, vol. 6, no. 3, pp. 257-276. 